\title{
Novel activation of peroxymonosulfate by biochar derived from rice husk toward oxidation of organic contaminants in wastewater
}

\author{
Pham Thi Huong ${ }^{\mathrm{a}, 1}$, Kim Jitae ${ }^{\mathrm{a}, 1}$, T.M. Al Tahtamouni ${ }^{\mathrm{b}}$, Nguyen Le Minh Tri ${ }^{\mathrm{c}, \mathrm{d}}$, Hak-Hyeon Kim ${ }^{\mathrm{e}}$, \\ Kyung Hwa Cho ${ }^{\mathrm{f}}$, Changha Lee ${ }^{\mathrm{g}, *}$ \\ ${ }^{a}$ Center for Advanced Chemistry, Institute of Research and Development, Duy Tan University, Da Nang, 550000, Vietnam \\ ${ }^{\mathrm{b}}$ Materials Science and Technology Program, College of Arts and Sciences, Qatar University, Doha 2713, Qatar \\ ${ }^{\mathrm{c}}$ Laboratory of Advanced Materials Chemistry, Advanced Institute of Materials Science, Ton Duc Thang University, Ho Chi Minh City, Vietnam \\ ${ }^{\mathrm{d}}$ Faculty of Applied Sciences, Ton Duc Thang University, Ho Chi Minh City, Vietnam \\ ${ }^{\mathrm{e}}$ Department of Civil and Environmental Engineering, University of Waterloo, Waterloo, Ontario, Canada \\ ${ }^{\mathrm{f}}$ School of Urban and Environmental Engineering, Ulsan National Institute of Science and Technology, UNIST-gil 50, Ulsan, 44919, Republic of Korea \\ ${ }^{\mathrm{g}}$ School of Chemical and Biological Engineering, Institute of Chemical Process (ICP), Seoul National University (SNU), 1 Gwanak-ro, Gwanak-gu, Seoul 08826, Republic of \\ Korea
}

\section{A R T I C L E I N F O}

\section{Keywords:}

Rice husk

Biochar

Organic

Pollutants

Peroxymonosulfate

Wastewater

\begin{abstract}
A B S T R A C T
In this study, novel activation of peroxymonosulfate (PMS) by biochar derived from rice husk (generally considered useless agricultural wastes in Vietnam) toward organic pollutants from wastewater was investigated. The basic properties of biochar were characterized through field-emission scanning electron microscopy (FE-SEM), elemental analysis (EA) and gas adsorption analysis (BET). Operating parameters including PMS concentration, dose of biochar and initial concentration of target pollutants (tetracycline and bisphenol A) were systematically studied. The results showed that biochar derived from rice husk effectively activated of PMS, leading to high degradation of organic pollutants in wastewater. The degradation efficiency of organic pollutants increased with increasing PMS concentration and amount of biochar. The reuse of rice husk biochar and the possible mechanism for PMS activation were proposed accordingly. In addition, the evaluation of potential available rice husk biomass in Vietnam was discussed. These findings suggest a novel rice husk biochar for activation of PMS toward toxic organic pollutants from wastewater.
\end{abstract}

\section{Introduction}

The development of industries has resulted in a lot of crucial issues in the industrialization and the most serious problem was the polluted wastewater discharge that largely contains organic and inorganic pollutants [1-5]. The organic contaminants have become a research spot in wastewater treatment and aroused considerable attention due to their toxicity, non-biodegradability and potential carcinogenicity, even human health threats, and economic development inhabitation [4-7]. The widely used of pharmaceutical and personal care products produced lager of organic pollutants in the water leading to environmental hazard as well as impacts on the ecosystems and the human health [8]. Antibiotics are one of the most popular compounds of the pharmaceutical which used in patient treatments. Tetracycline (TC) is the second most widely used antibiotics in the world, however, it is not completely metabolized by human and animal organisms, and approximately $75 \%$ of the ingested TC is excreted through the feces and urine [9]. The remaining of TC would be enter the surface water, groundwater, and even drinking water through surface runoff or leaching process.

However, TC may cause bacterial resistance, resulting in ecological destruction and threatening human health through bioaccumulation in the food chain $[1,4,8]$. Therefore, TC pollution is a serious issue need to concern for reducing its toxicity for environmental and human health.

Besides, the Bisphenol A is one of the highly produced industrial chemicals in the world and it widely used in almost of plastics and resins products [2]. Bisphenol A was detected in a large number of aquatic environments including surface water, ground water and wastewater and it generally referred as emerging contaminant in recent years [9-11]. In addition, many studies have been reported about

\footnotetext{
* Corresponding author.

E-mail addresses: taltahtamouni@qu.edu.qa (T.M. Al Tahtamouni), nguyenleminhtri@tdtu.edu.vn (N. Le Minh Tri), khcho@unist.ac.kr (K.H. Cho), leechangha@snu.ac.kr (C. Lee).

${ }^{1}$ Equal contribution.
} 
health effects of bisphenol A such as diabetes, reproductive disorders, obesity, birth defects, cardiovascular diseases and breast cancer [9-13]. Therefore, the development method to remove BPA from wastewater is necessary.

The different techniques were used to remove TC and BPA form wastewater such as membrane separation, adsorption, electrochemical and advanced oxidation processes (AOPs) [4,14-16]. Among them, advanced oxidation processes have received considerable attention in recent years. The AOPs include heterogeneous catalysis, homogeneous photochemical oxidation, ozone and their combination processes which were based on activation of titanium dioxide $\left(\mathrm{TiO}_{2}\right)$, hydrogen peroxide $\left(\mathrm{H}_{2} \mathrm{O}_{2}\right)$ and peroxymonosulfate (PMS) to provide hydroxyl radicals $\left(\mathrm{OH}^{*}\right)$ and sulfate radical $\left(\mathrm{SO}_{4}{ }^{-}{ }^{-}\right)$as oxidizing species. Sulfate radical $\left(\mathrm{SO}_{4}{ }^{-}{ }^{-}\right)$based AOPs has a higher redox potential $\left(\mathrm{E}_{0}=2.5-3.1 \mathrm{~V}_{\mathrm{vs}}\right)$ than the hydroxyl radical $\left(\mathrm{OH}^{\circ}, \mathrm{E}_{0}=1.8-2.7 \mathrm{~V}_{\mathrm{vs}}\right)$ has been increasingly applied for treatment of wastewater [14-18]. However, to generate the surface radicals, the PMS could be activated by using heat or activators such as transition metal catalyst, metal-free heterogeneous catalysts, ultraviolet and ultrasound. These activators can efficiently activate the PMS and showed high performance for removal of organic pollutants, but they have significant limitations in the application such as highcost, high energy consumption and metal leaching result in secondary contamination to water.

Therefore, the development of green activator for PMS activation is an area of active research and highly desired. The biochar is an environmentally friendly material which has been apply for wastewater treatment as adsorbent [18-24].

In addition, the rice husk is most available source in Vietnam produces more than 40 million tons of rice and the rice husk account for 20 percent of rice grains. This means around 8 million tons of rice husks are discharged into the environment, a huge volume of waste which, if not treated, will cause pollution. Therefore, the use of rice husk waste to produce the biochar in the treatment of wastewater will remarkably reduce the overall cost of wastewater treatment as well as solid waste treatment. Until now, a few studies have been done with activation of PMS by biochar for the decomposition of organic pollutants. Herein, for better understanding of the interaction between PMS and biochar, this study aims to investigate the removal of BPA and TC from wastewater using rice husk biochar activation of PMS.

\section{Material and methods}

\subsection{Chemicals}

All chemicals were reagent grade and used without further purification. Tetracycline (98\%, molecular formula: $\mathrm{C}_{22} \mathrm{H}_{24} \mathrm{~N}_{2} \mathrm{O}_{8} \cdot \mathrm{xH}_{2} \mathrm{O}$, molecular weight: 444.43), bisphenol A (98\%, molecular formula: $\mathrm{C}_{15} \mathrm{H}_{16} \mathrm{O}_{2}$, molecular weight: 228.3), Sodium persulfate $\left(\mathrm{Na}_{2} \mathrm{~S}_{2} \mathrm{O}_{8}\right.$, $97 \%)$, sodium thiosulfate $\left(\mathrm{Na}_{2} \mathrm{~S}_{2} \mathrm{O}_{3} \cdot 5 \mathrm{H}_{2} \mathrm{O}, 98 \%\right)$, disodium hydrogen phosphate (Na2HPO4, 98\%), sodium dihydrogen phosphate $\left(\mathrm{NaH}_{2} \mathrm{PO}_{4}\right.$, $98 \%$ ), and potassium iodide (KI, $\geq 98 \%$ ) were purchased from DapChem (Co, Ltd, Hai Phong, Vietmam). Methanol (98\%, $\left.\mathrm{CH}_{3} \mathrm{OH}\right)$ and ethanol $\left(97 \%, \mathrm{C}_{2} \mathrm{H}_{5} \mathrm{OH}\right)$ used without further purification. Ultrapure water was obtained from Milli-Q water purification (Millipore Co., USA) and used for the solution preparation.

\subsection{Production of biochar from rice husk waste}

Rice husk waste was collected from rice farm area located in Thai Binh province, North Vietnam. After that, the rice husk waste was washed with deionized water to remove impurities such as dirt, sand, and leaves then dried at $50{ }^{\circ} \mathrm{C}$ for $48 \mathrm{~h}$. The dried rice husks were sieved to obtain a uniform particle size range between 20 and $50 \mu \mathrm{m}$. Then $80 \mathrm{~g}$ of rice husk was pyrolyzed at temperature $450{ }^{\circ} \mathrm{C}$ for $4 \mathrm{~h}$ using a furnace under $\mathrm{N}_{2}$ gas at $500 \mathrm{cc} / \mathrm{min}$. After cooling to the room temperature $\left(22 \pm 1{ }^{\circ} \mathrm{C}\right)$, the rice husk biochar (RBC) was taken out and keep in in an airtight plastic container for further experiments.

\subsection{Experimental procedure and analysis}

Degradation of BPA and TC were carried out in a $50 \mathrm{~mL}$ conical flask placed on magnetic stirrers at room temperature $22 \pm 1{ }^{\circ} \mathrm{C}$. An amount of RBC was added into the solution, which contained desired concentrations of organic pollutants, PMS and phosphate buffer. The solution $\mathrm{pH}$ was fixed at $\mathrm{pH}=6.0$. The influent of $\mathrm{RBC}$ dose was identified with the dose range from 0.05 to $0.5 \mathrm{~g}$. The effect of PMS concentration on the removal of BPA and TC were done with the concentration of PMS varied from $2 \mathrm{mM}$ to $20 \mathrm{mM}$. The influent of initial organic pollutants concentration were identified with changing concentration of BPA and TC from 20 to $100 \mathrm{mg} / \mathrm{L}$. All of experiments were conducted in duplicate, and the data were reported as the mean with error bars. The samples were collected at regular time points $(2 \mathrm{~mL}$ samples were transferred to $20 \mathrm{~mL}$ vials filtered through $0.45 \mu \mathrm{m}$ fiberglass membrane before the addition of $0.5 \mathrm{~mL}$ sodium thiosulfate $2 \mathrm{M}$, and stored at $3{ }^{\circ} \mathrm{C}$ before being analyzed by HPLC. The HPLC (276A) system with Agilent C18 column $(150 \times 4.6 \mathrm{~mm}, 3.5 \mu \mathrm{m})$ coupled with a UV detector (set at a signal wavelength of 228 and $220 \mathrm{~nm}$ for BPA and TC, respectively) was used to analyzer the concentration of organic pollutants. The isocratic mobile phase consisted of $70 \%$ methanol and $30 \%$ water at a flow rate of $1 \mathrm{~mL} / \mathrm{min}$. Each experiment was run in triplicates and the control experiments with only RBC and PMS were also under the same condition.

Scanning electron microscopy (SEM) was applied to investigating the surface morphology of rice husk biochar (Hitachi S-3200 scanning electron microscopy). The elemental composition was detected by elementary analyzer (Elementar M-7968), and provided composition information of the weight fraction ( $w \mathrm{t} \%$ ) of contained elements, including carbon (C), hydrogen $(\mathrm{H})$ and oxygen $(\mathrm{O})$. The micro-porosity and BET specific surface were carried out by $\mathrm{N}_{2}$ adsorption at $77 \mathrm{~K}$ using Autosorb (ASAP 125). Finally, the surface functional groups of the RBC before and after the reaction were analyzed by the Fourier transform infrared (FTIR) spectrometer (Thermo Nicolet Nexus, ModelS470, Thermo Fisher Scientific Inc., USA), in the range of 400-4500 $\mathrm{cm}^{-1}$.

\section{Results and discussions}

\subsection{Basic properties of rice husk biochar}

\subsubsection{SEM analysis}

The surface morphology of raw rice husk and rice husk biochar were identified and the results are shown in Fig. 1. The surface morphology of biomass was smooth and low porous structure while the RBC showed the surface roughness with large of pores and activate sites. The result suggested that the pyrolyzed rice husk biomass was successfully changed the surface morphology as well as porosity structure and converted it into biochar. In general, the high porous structure of materials would be helpful in adsorption process [25-27].

\subsubsection{Elemental and specific surface area analysis}

The elemental composition and specific surface areas of materials were measured and the data presented in Table 1 . The specific surface area and total pore volume of rice husk biomass were $16.3 \mathrm{~m}^{2} / \mathrm{g}$ and $0.11 \mathrm{~cm}^{3} / \mathrm{g}$, respectively. However, the RBC showed greatly improvement in surface area and pore volume, which were $168.7 \mathrm{~m}^{2} / \mathrm{g}$ and $0.43 \mathrm{~cm}^{3} / \mathrm{g}$, respectively. It could be explained by the enlargement of small pores and the resulting collapse of partial porous structure, which offsets the contribution of the creation of new pores, leads to increase the specific surface area [3,28-30].

The result from elemental analysis showed the present of carbon (24.4\%), hydrogen $(8.7 \%)$ and oxygen $(21.1 \%)$ in the rice husk biomass. The amount of these elements were changed after pyrolyzed of 

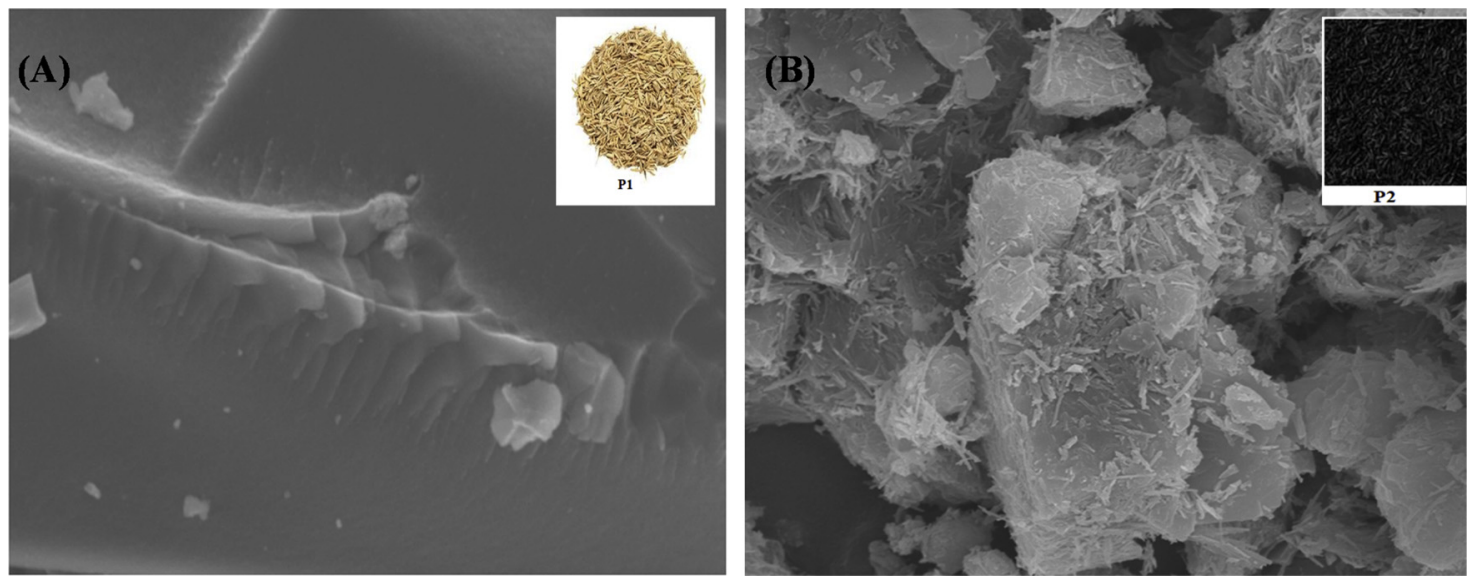

Fig. 1. SEM analysis: (A): Rice husk biomass and (B): Rice husk biochar.

rice husk biomass. The carbon and oxygen content rapidly increased by 46.2 and $36.5 \%$, respectively, indicated that rice husk biomass was converted into biochar with high content of carbon and more fractions of oxygenated.

\subsubsection{Zeta potential analysis}

To determine the point of zero charge of RBC, zeta potential analysis was applied, the details of result and discussion were displayed in Supporting Information (Text S1 and Fig. S1)

\subsubsection{FTIR analysis}

The FTIR spectra of RBC before and after the reaction were investigated within the characteristics region of $500-4500 \mathrm{~cm}^{-1}$ (Fig. S2). It can be seen that, the wide bands at $3250-3400 \mathrm{~cm}^{-1}$ could be assigned to the hydroxyl group $(\mathrm{O}-\mathrm{H})$ [3]. A band at $2900 \mathrm{~cm}^{-1}$ was attributed to the $\mathrm{C}-\mathrm{H}\left(\mathrm{CH}_{3}, \mathrm{CH}_{2}\right)$ stretching vibration. The band at $1700-1650 \mathrm{~cm}^{-1}$ was indicative of a stretching vibration of $\mathrm{C}=\mathrm{O}$ bonds associated with carboxylic acids or esters present in RBC. The adsorption band at $1495 \mathrm{~cm}^{-1}$ was related to $\mathrm{C}=\mathrm{C}$ stretching in aromatic structures [25]. The broad band in the region around 1130 and $1325 \mathrm{~cm}^{-1}$ were ascribed to the presence of aliphatic ethers $(\mathrm{C}-\mathrm{O}-\mathrm{C})$ and alcohols $(\mathrm{C}-\mathrm{O})$ stretching or phenols groups [28]. Finally, the small band at $850 \mathrm{~cm}^{-1}$ associated to $\mathrm{C}-\mathrm{H}$ aromatic groups [30,31]. The results from FTIR analysis confirmed the presence of oxygen-containing functional groups including $\mathrm{O}-\mathrm{H}, \mathrm{C}-\mathrm{O}, \mathrm{C}=\mathrm{O}$ and $\mathrm{C}-\mathrm{O}-\mathrm{C}$ in the structure of RBC. The infrared spectra of the RBC after the reaction showed a substantial decrease in peak intensity of $\mathrm{C}=\mathrm{O}$ peak absorbance and shrinking of the hydroxyl group absorbance. The FTIR results indicated that the oxygen-containing functional groups of RBC could activated the PMS for the enhancement removal efficiency of organic pollutants in the wastewater [30-32].

3.2. Degradation of BPA and TC using RBC activation of PMS in aqueous solution

\subsubsection{Effect of PMS concentration}

Fig. 2(a) and (b) exhibited the influent of different PMS concentration on the degradation rate of BPA and TC, respectively.
When the concentration of PMS increased from $1 \mathrm{mM}$ to $10 \mathrm{mM}$, the degradation rate of organic pollutants also increases correspondingly from 47 to $96.6 \%$ for BPA and $38.2-92.5 \%$ for TC, respectively. At high concentration of PMS, the formation of more surface radicals are available in the solution (as the concentration of PMS increased), leads to improve the probability of radicals attacking the organic pollutants. However, the degradation rate of BPA and TC were negligible when the PMS concentration up to $20 \mathrm{mM}$. The results suggested that the activation sites form RBC are unavailable for activated PMS or the byproducts during the degradation process compete to BPA and TC, thus no further increase in the degradation efficiency of organic pollutants [32-35].

\subsubsection{Effect of solution $p H$}

The solution $\mathrm{pH}$ is an important parameter affecting the oxidative ability of the RBC/PMS system [33]. In this study, the effect of solution $\mathrm{pH}$ on the degradation of BPA and TC was conducted in the $\mathrm{pH}$ range of 3.0-10.

Fig. S3 showed the degradation efficiency of organic pollutants lightly decrease with the increase in initial $\mathrm{pH}$ from 3.0 to 6.0 in the RBC/ PMS system, while the removal efficiency significantly declines with further increase in $\mathrm{pH}$ to $8.0-10$. When the $\mathrm{pH}$ solution were 3.0 and 6.0, the degradation efficiencies for BPA and TC were 98.6 and $95.7 \%$; 94.1 and $92.9 \%$, respectively. Besides, at the $\mathrm{pH}=10$, the degradation efficiencies of BPA and TC were rapidly decreased by 68.5 and $60.7 \%$, respectively. At the low solution $\mathrm{pH}(\mathrm{pH}=3.0)$ the surface charge of $\mathrm{RBC}$ was positive due to the $\mathrm{pH}_{\mathrm{pzc}}=3.75$ (see in Supporting Information Text S1 and Fig. S1), thus improvement in PMS adsorption occurs onto the $\mathrm{RBC}$ and more $\mathrm{HSO}^{-}, \mathrm{SO}_{4}{ }^{-}$, and $\mathrm{HO}{ }^{\circ}$ can produce. When the solution $\mathrm{pH}$ increase (higher than $\mathrm{pH}_{\mathrm{pzc}}$ ), the surface of $\mathrm{RBC}$ becomes negative charge, leading to decrease the interaction between $\mathrm{RBC}$ and PMS. However, the PMS become unstable under high $\mathrm{pH}$ solution $(\mathrm{pH}=10)$, resulting in less effect of $\mathrm{RBC} / \mathrm{PMS}$ system on the degradation of BPA and TC. The lower degradation efficiency was observed due to the weak oxidative capability at high $\mathrm{pH}$ as compared to the low $\mathrm{pH}$ solution. Based on the result, the $\mathrm{pH}$ of 6.0 is selected for further studies.

Table 1

Chemical composition and specific surface area of materials.

\begin{tabular}{|c|c|c|c|c|c|c|}
\hline \multirow[t]{2}{*}{ Materials } & \multirow[t]{2}{*}{ Specific surface area $\left(\mathrm{m}^{2} / \mathrm{g}\right)$} & \multirow[t]{2}{*}{ Total pore volumes $\left(\mathrm{cm}^{3} / \mathrm{g}\right)$} & \multicolumn{4}{|c|}{ Elemental composition (\%) } \\
\hline & & & $\mathrm{C}$ & $\mathrm{H}$ & $\mathrm{O}$ & Others \\
\hline Rice husk biomass & 16.3 & 0.16 & $24.4 \pm 0.31$ & $8.7 \pm 0.11$ & $21.1 \pm 0.06$ & $45.8 \pm 0.27$ \\
\hline Rice husk biochar & 168.7 & 0.48 & $46.2 \pm 0.28$ & $10.9 \pm 0.14$ & $26.5 \pm 0.13$ & $16.4 \pm 0.16$ \\
\hline
\end{tabular}



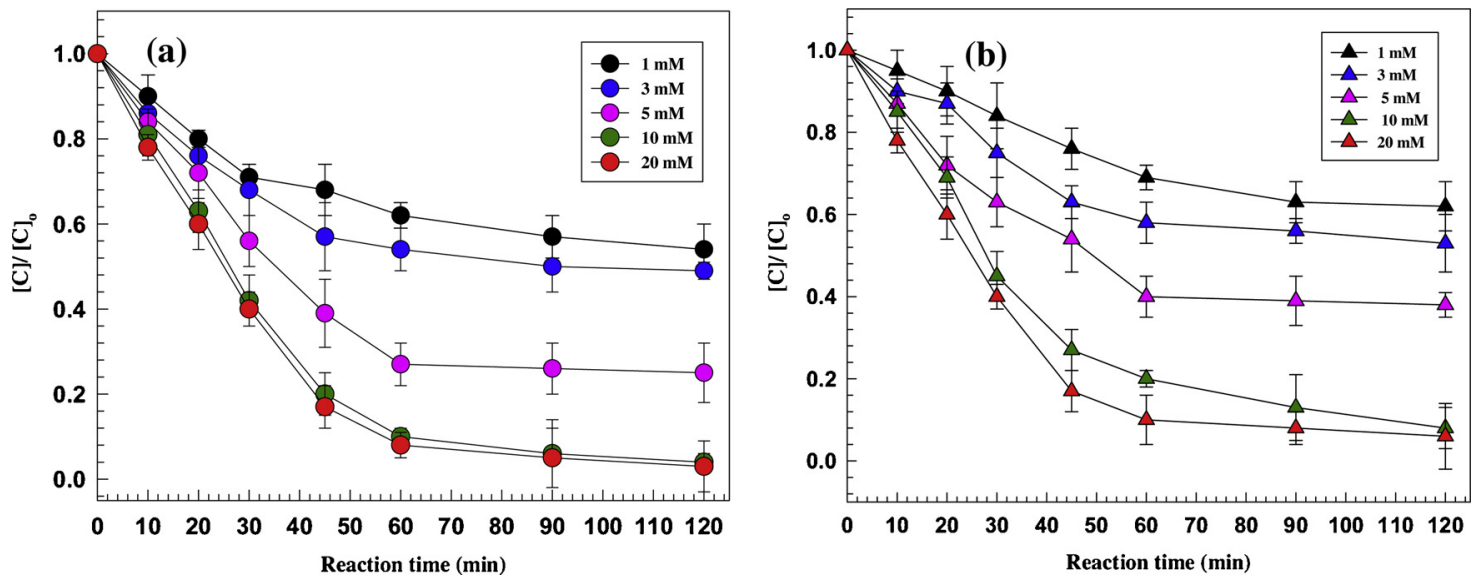

Fig. 2. Effect of PMS concentration on the degradation of (a): BPA and (b): TC.
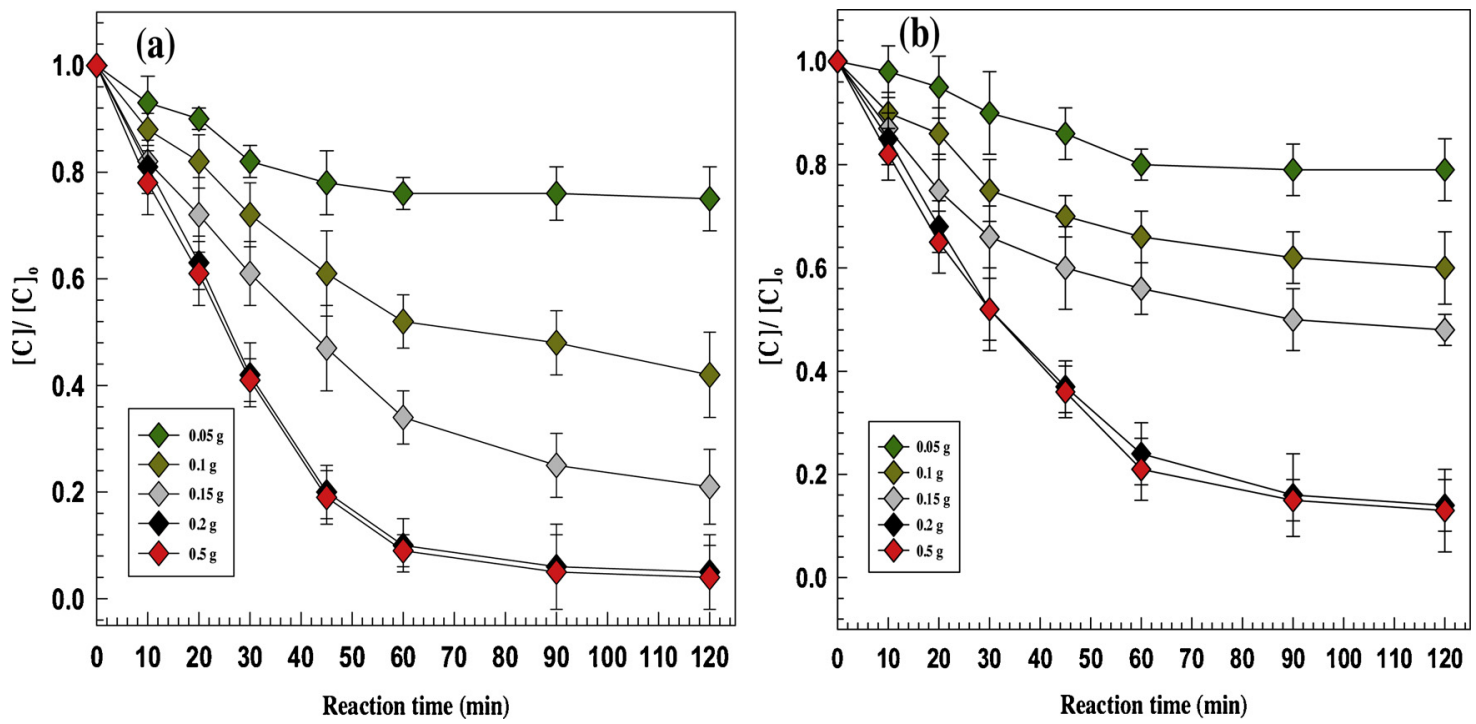

Fig. 3. Effect of RBC dose on the degradation of (a): BPA and (b): TC.

\subsubsection{Effect of RBC dose}

The degradation of BPA and TC under different amount of RBC were investigated and the results are shown in Fig. 3.

The degradation of organic pollutants significantly enhanced with the increase of RBC dose from 0.05 to $0.5 \mathrm{~g}$. The removal rates of BPA and TC per unit weight of adsorbent rapidly increased up to 96.3 and $93.4 \%$ as the RBC dose was increased to $0.2 \mathrm{~g}$ within $60 \mathrm{~min}$.

The increase of RBC dose leading to improve the number of adsorption sites for a given concentration of BPA and TC as well as generate sulfate radicals [32,33]. However, above a dosage of $0.2 \mathrm{~g}$, the percentage removal of BPA and TC were not further increased, because the active sites adsorption are blocked and all sulfate radicals are generated at a high dosage. Hence, $0.2 \mathrm{~g}$ of RBC was chosen as the optimum dosage for further experiments.

In addition the removal performance of BPA and TC by using several different materials (including only PMS and only biochar) were investigated and the results are listed in Fig. 4. The degradation of BPA and TC were no appreciable with only persulfate confirmed there were no reaction between PMS and organic pollutants. The removal of BPA and TC by RBC within 120 min of reaction time were 28.3 and $22.5 \%$, respectively. The result indicated that, the adsorptive removal of BPA and TC in the RBC/ PMS system mention above including adsorption and degradation by the sulfate radicals. The adsorption onto the surface of RBC only account for small part while the degradation plays a major role for the removal of BPA and TC.

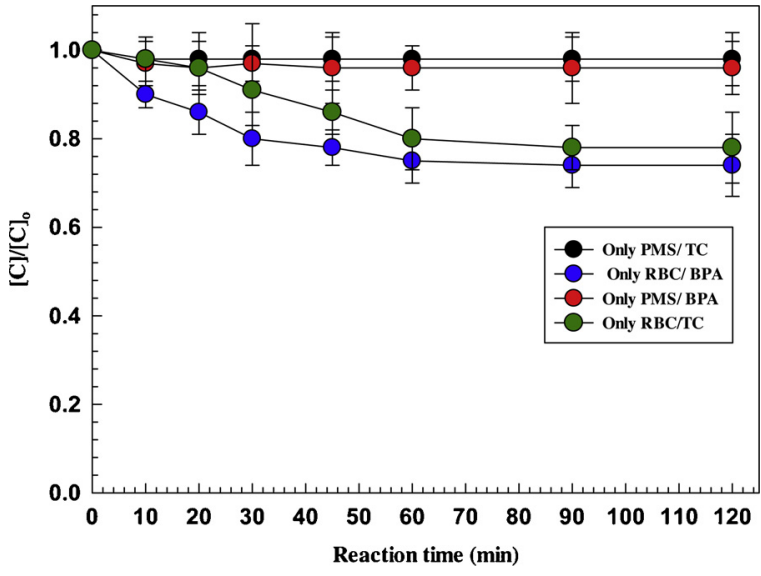

Fig. 4. Effect of different materials on the removal of BPA and TC.

\subsubsection{Effect of BPA and TC initial concentration}

The degradation rate of BPA and TC $(20-100 \mathrm{mg} / \mathrm{L})$ were investigated and showed in Fig. 5. It can be observed that lower initial concentration of BPA and TC had better degradation effect. The degradation rate of BPA and TC were 94.5 and $90.3 \%$, respectively at $20 \mathrm{mg} / \mathrm{L}$ of initial concentration. However, the removal of BPA and TC 

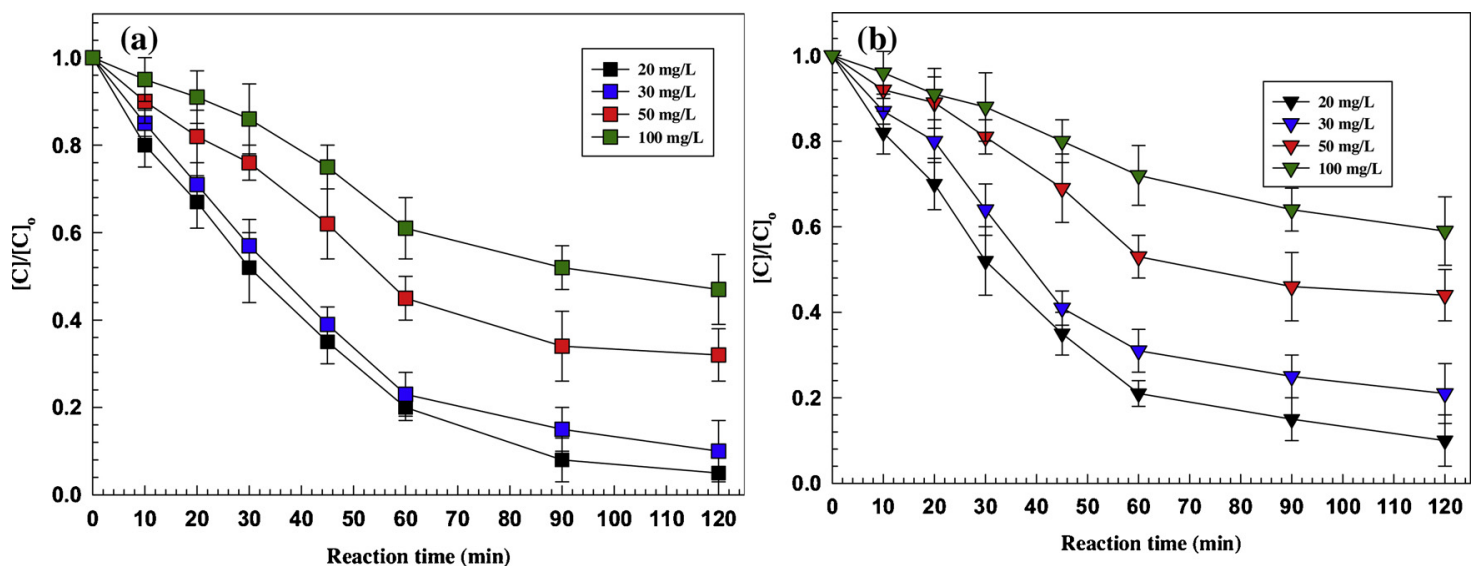

Fig. 5. Effect of initial concentration on the removal of BPA and TC.

rapidly decreased at 53.5 and $41.9 \%$, respectively, when the initial concentration increased up to $100 \mathrm{mg} / \mathrm{L}$. At low concentration of pollutants, more $\mathrm{SO}_{4}{ }^{-}$- radicals were generated due to less competition between PMS and pollutants on the surface of RBC, resulting in high removal efficiencies of BPA and TC. At high concentration of BPA and TC, the activation of PMS to produce $\mathrm{SO}_{4}{ }^{-{ }^{-}}$radicals by $\mathrm{RBC}$ was inhibited, leading to decrease in the removal efficiency of BPA and TC.

\subsubsection{Stability and reusability of $R B C$}

The rice husk biochar not only exhibited great potential to activated PMS in the lab-scale elimination of organic pollutants, but is also expected to be scalable for large-scale applications in industry. Therefore, the recovery and recycling ability of $\mathrm{RBC}$ was studied by repeating five times of the removal of BPA and TC experiment using RBC/PMS.

After each experiment, the RBC was collected by centrifuging at $1500 \mathrm{rpm}$, washing with $50 \mathrm{~mL}$ ethanol $30 \%$ and then drying at $50{ }^{\circ} \mathrm{C}$ for $12 \mathrm{~h}$ before being continuously reused for a new cycle. The removal efficiency of BPA and TC after 5 cycles are shown in Fig. 6.

It can be seen that the RBC/ PMS system continuously showed high degradation efficiency of BPA and TC with less than 15\% loss after five cycles. This slight reduction in removal efficiency of BPA and TC due to some loss of RBC during its recovery via centrifugation or washing process. Based on the result, RBC would be consider as cost-effective remediation of BPA and TC contaminated in wastewater.

In order to further investigate the application of RBC/PMS, the comparison among various biochars/PMS system for organic pollutants removal were made (refer to Text S2 and Table S1).

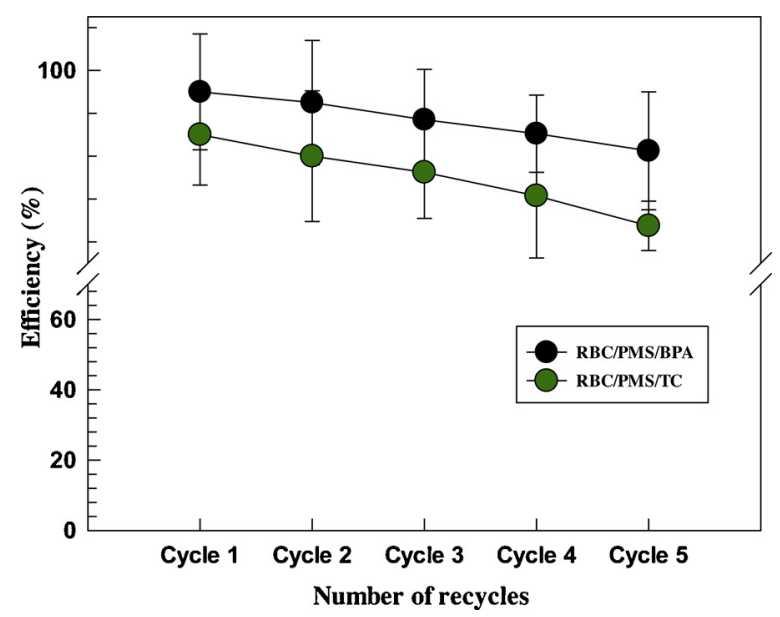

Fig. 6. Reusability of RBC.

\subsubsection{Identify the reactive oxygen species}

To identify the reactive oxygen species, ethanol (EtOH, 0.5 M) was used as scavenger for both $\mathrm{HO}^{\circ}$ and $\mathrm{SO}_{4}{ }^{-}$due to its high reactivity, and tertiary butanol (TBA, 0.5 M) and furfuryl alcohol (FFA, $0.5 \mathrm{M}$ ) were selected as scavengers for $\mathrm{HO}^{\circ}$ and ${ }^{1} \mathrm{O}_{2}$, respectively [36,37,38].

From Fig. S4, it can be seen that, in the present of TBA the removal efficiencies of BPA and TC significantly decreased from 96.3 to $47.6 \%$ and 93.4 to $43.2 .5 \%$, respectively. With the addition of EtOH, the degradation efficiencies of BPA and TC dramatically declines by 34.1 and $29.9 \%$ for BPA and TC, respectively. However, when the FFA introduced into the RBC/PMS system, the removal efficiencies of BPA and TC were almost terminated as compared to original once without radicals scavenger.

This result indicated that, both $\mathrm{HO}^{\circ}$ and $\mathrm{SO}_{4}{ }^{-}$favored for the removal of BPA and TC in the RBC/ PMS system but $\mathrm{HO}^{\circ}$ was the dominant free radical.

\subsubsection{Possible mechanism for removal of $B P A$ and $T C$ by $R B C$ activated PMS}

It is well-known that rice hush biochar had defect structure with containing the functional groups such as carbonyl $(\mathrm{C}=\mathrm{O})$, carboxylic $(\mathrm{COOH})$ and phenol $(\mathrm{OH})$ [38]. According to the previous studies the defect structure of biochar can donate the electron to PMS [26-30]. The activation of PMS by biochar can be described as following:

Firstly, the PMS adsorb on the surface of RBC, then the donate electron from RBC move to PMS and provide hydroxyl radicals $\left(\mathrm{OH}^{*}\right)$ and sulfate radical $\left(\mathrm{SO}_{4}{ }^{-}\right)$as oxidizing species [21,22].

The previous studies confirmed the electron from defect structure of biochar can donate to PMS and activation PMS for providing hydroxyl radicals $\left(\mathrm{OH}^{*}\right)$ and sulfate radical $\left(\mathrm{SO}_{4}{ }^{-}\right)$as oxidizing species [22-24]. In next step, the hydroxyl radicals $\left(\mathrm{OH}^{\circ}\right)$ and sulfate radical $\left(\mathrm{SO}_{4}{ }^{-}\right)$ attacked the BPA and TC, then degraded these pollutants into smaller intermediates and finally into $\mathrm{CO}_{2}$ and $\mathrm{H}_{2} \mathrm{O}$ (See in Fig. 7).

\subsubsection{Removal of BPA and TC in wastewaters}

In order to investigate the potential application of RBC/ PMS to the real environmental condition, the removal of BPA and TC in wastewaters were conducted and the results were reported in Supporting Information (refer to text S3, Table S2 and Fig. S5).

\subsubsection{Environmental impact}

The strong economic growth and urbanization rates in the last decade in Vietnam, leading to increase number of solid wastes. Rice is major Agricultural production in Vietnam, it increasing year by year since 1993 (see in Fig. 8). According to the Vietnam Institute of Agricultural Sciences, the rice husk account for 20 percent of total rice production. Therefore, a larger of waste amount from rice farms 


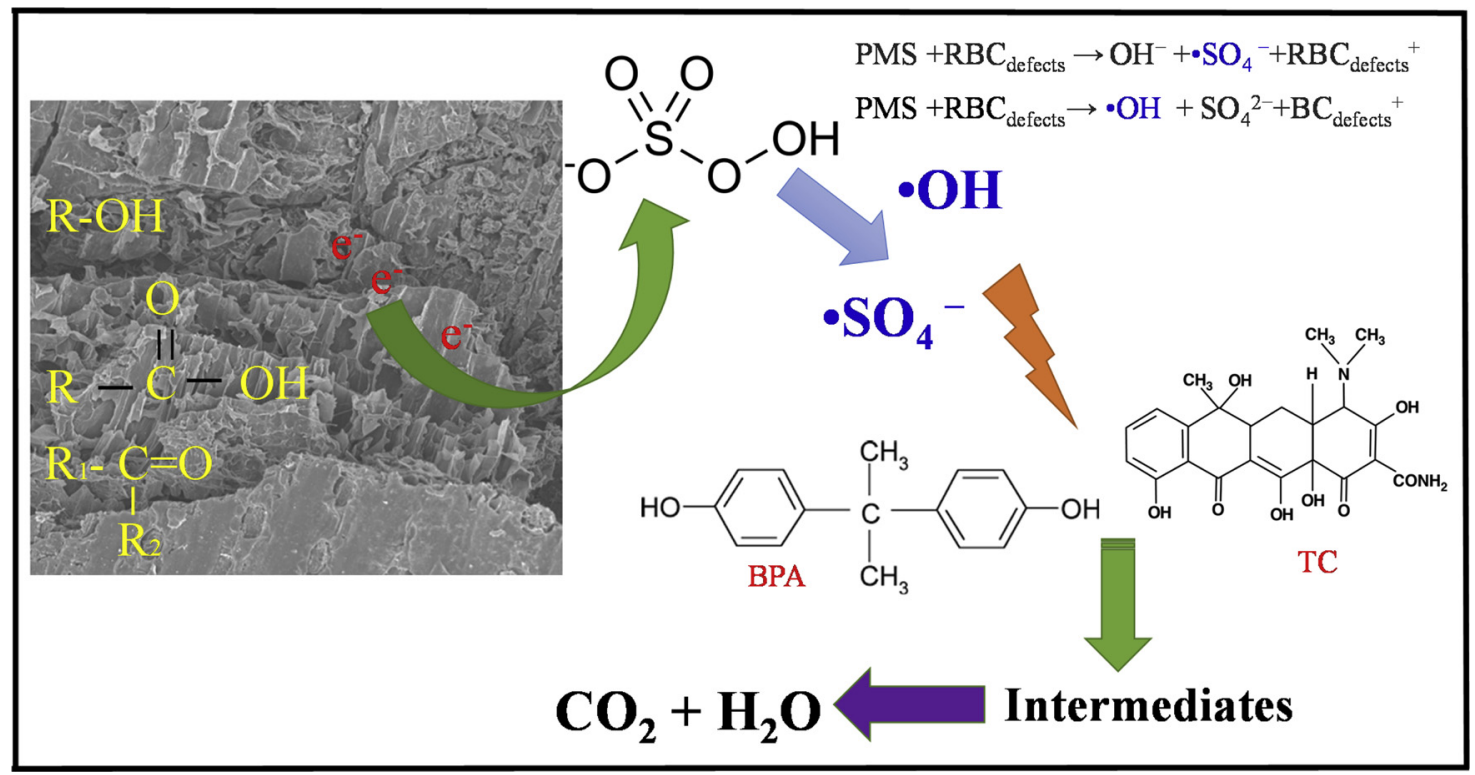

Fig. 7. Mechanism for removal of BPA and TC by RBC activated PMS.

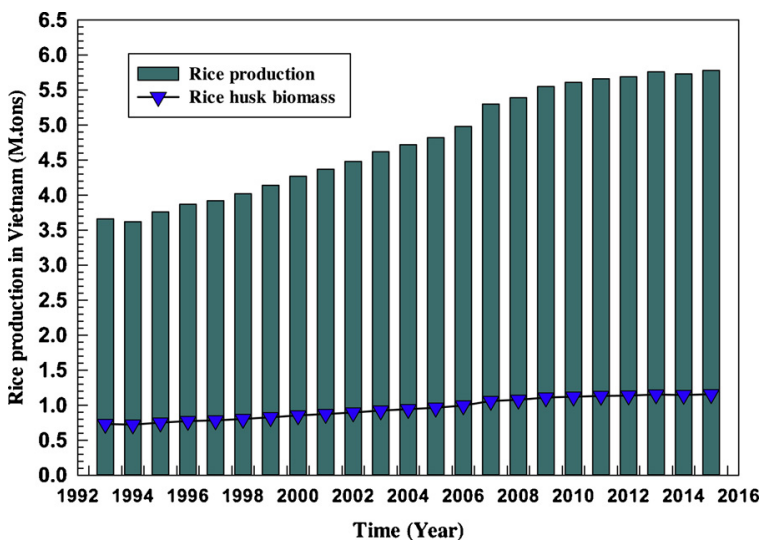

Fig. 8. Rice and rice husk biomass production in Vietnam.

produced and discharge into environment.

The results from the study demonstrate that BPA and TC contaminated in wastewater can efficiently remediated by RBC activation of PMS. Furthermore, the method of PMS activation shows great potential of RBC as a novelty activator for PMS. On one hand, because of the abundance of feedstock materials, the use of rice husk waste to produce the biochar in the treatment of wastewater will remarkably reduce the overall cost of wastewater treatment as well as solid waste treatment.

\section{Conclusions}

In this study, the biochar derived from rice husk waste was used as effectively activator for activation of PMS in order to remove the toxic BPA and TC from wastewater. The RBC/PMS exhibited more than $90 \%$ the removal efficiency of BPA and TC within $60 \mathrm{~min}$ of reaction time, $0.2 \mathrm{~g}$ dose and $5 \mathrm{mM}$ of PMS. It also displayed an excellent the stability for degradation of BPA and TC with less than 15\% loss in the removal efficiency after five cycles. The possible activation mechanism of PMS by RBC based on the defect structure of biochar which donated electrons to PMS and generating hydroxyl and sulfate radicals. In the file application tested, RBC/PMS was applied to remove BPA and TC from industrial wastewaters. The removal efficiencies of BPA and TC were 90.3 and $87.2 \%$, respectively, which demonstrated the promising of
RBC/PMS for treatment of wastewater containing BPA and TC. Based on these findings, RBC/PMS could be utilized as high potential activator of PMS for removal of organic pollutants from wastewaters.

\section{Declaration of Competing Interest}

The authors do not have any conflict of interests to declare.

\section{Acknowledgment}

This work was supported by the Korea Ministry of Environment as "The SEM projects" (RE201805163)

\section{Appendix A. Supplementary data}

Supplementary material related to this article can be found, in the online version, at doi:https://doi.org/10.1016/j.jwpe.2019.101037.

\section{References}

[1] H.R. Pouretedal, N. Sadegh, Effective removal of Amoxicillin, Cephalexin, Tetracycline and Penicillin G from aqueous solutions using activated carbon nanoparticles prepared from vine wood, J. Water Process Eng. 1 (2014) 64-73.

[2] T.D. Nguyen, K. Jitae, N.M. Viet, P.Q. Thang, P.T. Huong, Combination of $\mathrm{La}^{-\mathrm{TiO}_{2}}$ and activated car bon fiber for degradation of toxic organic pollutants under visible light, J. Environ. Chem Eng. 7 (2019) 103180.

[3] P.T. Huong, K. Jitae, B.L. Giang, T.D. Nguyen, P.Q. Thang, Novel lanthanummodified activated carbon derived from pine cone biomass as ecofriendly bio-sorbent for removal of phosphate and nitrate in wastewater, Rend. Fis. Acc. Lincei 30 (2019) 637-647.

[4] N.M. Viet, D.Q. Trung, B.L. Giang, N.L.M. Tri, P. Thao, T.H. Pham, F.Z. Kamand, T.M.Al Tahtamouni, Nobel metal-doped graphitic carbon nitride photocatalyts for enhancement photocatalytic decomposition of antibiotic pollutant in wastewater under visible light, J. Water Process Eng. 32 (2019) 100954.

[5] P.T. Huong, B.K. Lee, K. Jitae, C.H. Lee, Nitrophenols removal from aqueous medium using Fe-nano mesoporous zeolite, Mater. Des. 101 (2016) 210-217.

[6] G. Fang, W. Wu, Y. Deng, D. Zhou, Homogenous activation of persulfate by different species of vanadium ions for PCBs degradation, Chem. Eng. J. 323 (2017) 84-95.

[7] Q. Chen, Y. Zhang, D.D. Zhang, Y.Q. Yang, Ag and N co-doped $\mathrm{TiO}_{2}$ nanostructured photocatalyst for printing and dyeing wastewater, J. Water Process Eng. 16 (2017) $142-150$.

[8] H.R. Pouretedal, N. Sadegh, Effective removal of Amoxicillin, Cephalexin, Tetracycline and Penicillin G from aqueous solutions using activated carbon nanoparticles prepared from vine wood, J. Water Process Eng. 1 (2014) 64-73.

[9] L. Zhao, Y. Ji, D. Kong, J. Lu, Q. Zhou, X. Yin, Simultaneous removal of bisphenol A and phosphate in zero-valent iron activated persulfate oxidation process, Chem. Eng. J. 303 (2016) 458-466.

[10] J. Li, N. Liang, X. Jin, D. Zhou, H. Li, M. Wu, B. Pan, The role of ash content on 
bisphenol Asorption to biochars derived from different agricultural wastes, Chemosphere 171 (2017) 66-73.

[11] B. Chen, D. Zhou, L. Zhu, Transitional adsorption and partition of nonpolar and polar aromatic contaminants by biochars of pine needles with different pyrolytic temperatures, Environ. Sci. Technol. 42 (2008) 5137-5143.

[12] J. Michałowicz, Bisphenol A - sources, toxicity and biotransformation, Environ. Toxicol. Phar 37 (2014) 738-758.

[13] J.R. Rochester, Bisphenol A and human health: a review of the literature, Reprod. Toxicol. 42 (2013) 132-155.

[14] C. Zhang, C. Lai, G. Zeng, D. Huang, C. Yang, Y. Wang, Y. Zhou, M. Cheng, Efficacy of carbonaceous nanocomposites for sorbing ionizable antibiotic sulfamethazine from aqueous solution, Water Res. 95 (2016) 103-112.

[15] F. Conzuelo, M. Gamella, S. Campuzano, A.J. Reviejo, J.M. Pingarrón, Disposable amperometric magneto-immunosensor for direct detection of tetracyclines antibiotics residues in milk, Anal. Chim. Acta 737 (2012) 29-36.

[16] P.T. Huong, B.K. Lee, K. Jitae, C.H. Lee, Improved removal of 2-chlorophenol by a synthesized Cu-nanozeolite, Process Saf. Environ. Prot. 100 (2016) 272-280.

[17] P.T. Huong, B.K. Lee, K. Jitae, C.H. Lee, Improved adsorption properties of a nanozeolite adsorbent toward toxic nitrophenols, Process Saf. Environ. Prot. 104 (2016) 314-322.

[18] X.-D. Zhu, Y.-J. Wang, R.-J. Sun, D.-M. Zhou, Photocatalytic degradation of tetracycline in aqueous solution by nanosized $\mathrm{TiO}_{2}$, Chemosphere 92 (2013) 925-932.

[19] H. Sun, X. Peng, S. Zhang, S. Liu, Y. Xiong, S. Tian, J. Fang, Activation of peroxymonosulfate by nitrogen-functionalized sludge carbon for efficient degradation of organic pollutants in water, Bioresour. Technol. 241 (2017) 244-251.

[20] P.R. Shukla, S. Wang, H. Sun, H.M. Ang, M. Tadé, Activated carbon supported cobalt catalysts for advanced oxidation of organic contaminants in aqueous solution, Appl. Catal. B 100 (2010) 529-534.

[21] F. Ghanbaric, M. Ahmadi, Application of peroxymonosulfate and its activation methods for degradation of environmental organic pollutants: review, Chem. Eng. J. 310 (2017) 41-62.

[22] G. Fang, C. Liu, J. Gao, D.D. Dionysiou, D. Zhou, Manipulation of persistent free radicals in biochar to activate persulfate for contaminant degradation, Environ. Sci. Technol. 49 (2015) 5645-5653.

[23] G. Fang, C. Zhu, D.D. Dionysiou, J. Gao, D. Zhou, Mechanism of hydroxyl radical generation from biochar suspensions: implications to diethyl phthalate degradation, Bioresour. Technol. 176 (2015) 210-217.

[24] Y. Wu, J. Guo, Y. Han, J. Zhu, L. Zhou, Y. Lan, Insights into the mechanism of persulfate activated by rice straw biochar for the degradation of aniline, Chemosphere 200 (2018) 373-379.
[25] P.T. Huong, B.K. Lee, K. Jitae, C.H. Lee, M.N. Chong, Acid activation pine cone waste at differences temperature and selective removal of $\mathrm{Pb}^{2+}$ ions in water, Process Saf. Environ. Prot. 100 (2016) 80-90.

[26] N.T. Nham, T.M.Al Tahtamouni, T.D. Nguyen, P.T. Huong, K. Jitae, N.M. Viet, N.V. Noi, N.T.M. Phuong, N.T.H. Anh, Synthesis of iron modified rice straw biochar toward arsenic from groundwater, Mater. Res. Express 6 (2019) 115528.

[27] A. Ejraei, M.A. Aroom, A.Z. Saravani, Wastewater treatment using a hybrid system combining adsorption, photocatalytic degradation and membrane filtration processes, Water Process Eng. 28 (2019) 45-53.

[28] P.Q. Thang, K. Jitae, B.L. Giang, N.M. Viet, P.T. Huong, Potential application of chiken manure biochar towards toxic phenol and 2,4-dinitrophenol in wastewaters, J. Environ. Manag. 251 (2019) 109556.

[29] Z.M. Chen, B.L. Chen, D.D. Zhou, W.Y. Chen, Bisolute sorption and thermodynamic behavior of organic pollutants to biomass-derived biochars at two pyrolytic temperatures, Environ. Sci. Technol. 46 (2012) 12476-12483.

[30] G.D. Fang, J. Gao, C. Liu, D.D. Dionysiou, Y. Wang, D.M. Zhou, Key role of persistent free radicals in hydrogen peroxide activation by biochar: implications to organic contaminant degradation, Environ. Sci. Technol. 48 (2014) 1902-1910.

[31] L. Klüpfel, M. Keiluweit, M. Kleber, M. Sander, Redox properties of plant biomassderived black carbon (biochar), Environ. Sci. Technol. 48 (2014) 5601-5611.

[32] D. Mohan, A. Sarswat, Y.S. Ok, C.U. Pittman Jr., Organic and inorganic contaminants removal from water with biochar, a renewable, low cost and sustainable adsorbent - a critical review, Bioresour. Technol. 160 (2014) 191-202.

[33] Y.H. Guan, J. Ma, X.C. Li, J.Y. Fang, L.W. Chen, Influence of pH on the formation of sulfate and hydroxyl radicals in the UV/Peroxymonosulfate system, Environ. Sci. Technol. 45 (2011) 9308-9314.

[34] X. Wei, N. Gao, C. Li, Y. Deng, S. Zhou, L. Li, Zero-valent iron (ZVI) activation of persulfate (PS) for oxidation of bentazon in water, Chem. Eng. J. 285 (2016) 660-670.

[35] G. Fang, J. Gao, C. Liu, D.D. Dionysiou, Y. Wang, D. Zhou, Key role of persistent free radicals in hydrogen peroxide activation by biochar: implications to organic contaminant degradation, Environ. Sci. Technol. 48 (2014) 1902-1910.

[36] L. Khachatryan, B. Dellinger, Environmentally persistent free radicals (EPFRs)-2. Are free hydroxyl radicals generated in aqueous solutions? Environ. Sci. Technol. 45 (2011) 9232-9239.

[37] J. Kibet, L. Khachatryan, B. Dellinger, Molecular products and radicals from pyrolysis of lignin, Environ. Sci. Technol. 46 (2012) 12994-13001.

[38] S. Liao, B. Pan, H. Li, D. Zhang, B. Xing, Detecting free radicals in biochars and determining their ability to inhibit the germination and growth of corn, wheat and rice seedlings, Environ. Sci. Technol. 48 (2014) 8581-8587. 